\title{
A police specialist rape investigation unit: a comparative analysis of performance and victim care
}

Philip N. S. Rumney, Duncan McPhee, Rachel A. Fenton and Anneleise Williams

This article examines quantitative and qualitative data in an analysis of the workings of a specialist rape investigation unit and compares its performance with a non-specialist investigative approach. This is the first study to examine the work of a specialist rape investigation unit in this way. The research finds that the specialist unit outperformed the non-specialist investigative approach in many, though not all performance measures, including charging and 'reached court' rates in rape cases, retention of cases characterised by complex victim vulnerability, allocation of Sexual Assault Investigation Trained (SAIT) officers, rate of referral to Independent Sexual Violence Advisors (ISVA) and accuracy of crime recording. Further, police officer interview data suggest that team working and support, communication and a sense of common purpose were distinctive features of the specialist unit, when contrasted to experience of working in a non-specialist policing environment. These findings have policy and resource implications for the policing of rape and the need to achieve the best possible investigative standards in sexual offence cases, including the provision of appropriate care and addressing the needs of highly vulnerable victims. The article concludes by arguing that there is a growing body of evidence to suggest that investigative specialism is a crucial element in the police response to rape.

\section{Introduction}

The response of the police service to the investigation of rape allegations continues to be a major concern for government, criminal justice agencies, media and specialist support services. Amid criticism concerning such things as victim care, investigative standards and case outcomes (Kelly et al. 2005, IPCC 2010, Angiolini 2015) the police service in England and Wales has made significant efforts to address these and other concerns (Stern 2010, Horvath and Yexley 2012, Angiolini 2015). One means by which the police service has sought to improve its response to rape has been through the creation of specialist investigation units with the aim of, inter alia improving victim care and engagement, the quality of police investigations and inter-agency working. As of April 2012, of 43 police forces, 17 had 
specialist rape or sexual assault units, five had partially specialist units and two were in the process of creating a unit (Westmarland et al. 2012, p. 2). Today, specialist units operate within the context of large year-on-year increases in recorded allegations of rape and sexual assault (Office of National Statistics 2018), increasing case complexity and significantly reduced financial resourcing (APCC 2015, Barrett 2015, HMICFRS 2017). Further, in a 2011 Association of Chief Police Officers report, it was observed: ' ... there is insufficient empirical data available on which to base any firm conclusions as to the benefits of adopting dedicated investigation team approach' [sic] (ACPO 2011, p. 5). This study addresses this evidential gap by using quantitative and qualitative data to comparatively analyse a specialist and non-specialist policing response to rape. It examines the performance of Avon and Somerset Constabulary's 'Operation Bluestone', a specialist rape investigation unit, with a non-specialist comparator. The remit of Bluestone was the investigation of rape and other serious sexual offences in the city of Bristol involving victims 14 years and older. The evaluation uses new qualitative and quantitative data relating to allegations of rape and attempted rape to examine the progression of cases within Bluestone and the comparator, focusing on issues of attrition, victim care, the impact of vulnerability, and accuracy of crime recording. This is the first time an analysis of this type has been conducted on the work of a specialist rape investigation unit. The article will proceed by examining the history and work of specialist rape investigation units.

\section{The existing literature on specialist policing in rape and sexual offence cases}

In the UK, the need for a specialist approach to child abuse and rape cases was identified from the 1980s onwards (Blair 1985, Lloyd and Burman 1996). One of the earliest domestic examples of investigative specialism was the creation of a unit comprising five female police officers by Thames Valley Police following the notorious 1982 BBC documentary, A Complaint of Rape in which a rape complainant was treated in a dismissive and hostile manner by detectives (Foley 1990). The objectives under-pinning the creation of specialist units have remained largely unchanged over time (Metropolitan Police Authority 2002a, 2002b, Avon and Somerset Constabulary 2011) and while specialist units appear to have public support (Farand 2016) there is only limited evidence illustrating how a specialised response to rape may deliver benefits in terms of policing performance. The international literature has examined investigative specialism in the context of a range of crimes, 
including domestic violence and sexual offences. For instance, recent research found that a specialist domestic violence police unit led to an increase in the number of cases progressing through the criminal justice process (Regoeczi and Hubbard 2018). Earlier research on the impact of specialism in domestic violence cases has found mixed results (van Staden and Lawrence 2010). This has resulted, in part, from differing study methodologies, lack of scientific rigour and robust comparative data (Regoeczi and Hubbard 2018, p. 4).

Research examining investigative specialism in cases of rape and sexual assault is quite limited, but largely positive. An early, small scale North American study that compared police responses before and after the introduction of a specialist sexual offences investigative unit suggested an improvement in officer attitudes and other improvements that only 'occurred at points of least resistance' (LaFree 1989, pp. 80-89). More recent data from Australia found that victims of sexual assault viewed a specialist police unit response more favourably than a non-specialist response across all measures, including victim care, updating, access to services and timeliness of response (Powell and Cauchi 2013, pp. 238239). Similarly, in a study of police officers and other professional stakeholders it was found that Australian specialist unit reforms were viewed very positively in several areas including: inter-agency working, victim satisfaction and facilitation of communication (Powell and Wright 2011-2012).

In 2010, the Home Office published the results of a pilot study based on interviews with officers who worked in a specialist sexual assault investigation unit. The study found that officers perceived the unit as creating a 'joint working' approach (van Staden and Lawrence 2010 , p. 12) in which detectives and a SAIT officer ${ }^{1}$ worked together in progressing the investigation. It was argued that this interalia, improved victim support, sped up the investigative process, allowed for continuity in terms of staffing, reduced victim withdrawal, improved officer confidence in dealing with sexual offence cases and 'increased confidence in each other's ability' (van Staden and Lawrence 2010, pp. by interviewees (Westmarland

\footnotetext{
${ }^{1}$ The research makes reference to SOIT (Sexual Offences Investigative Trained) officers. This article uses the term SAIT (Sexual Assault Investigation Team) officer throughout for the purpose of consistency given that the Bluestone and comparator area use the term 'SAIT'. The differing terminology reflects differences between individual police forces.
} 
et al. 2012), but neither study examined case files to test the accuracy of interviewee perceptions or utilised a comparator to measure improvement. In the context of the broader debate concerning austerity and police funding, forces now appear to be (re)assessing their strategies with regard to units specialising in sexual offences. Most recently, Greater Manchester Police (GMP) and the Metropolitan Police reassigned sexual offence unit detectives to local teams (Williams and Keeling 2017, Beckford 2018, Metropolitan Police 2018). In the case of the GMP, its Serious Sexual Offences Unit is the latest unit to be disbanded following closures in several other force areas in recent years. The closure of specialist units runs counter to the findings of successive HMICFRS reports examining investigative specialism in criminal cases. Most recently, HMICFRS, noted: 'we found a continuing disparity in the quality of investigations undertaken in specialist units where the quality of investigation is generally good and non-specialist units where all too often the quality of investigation is poor' (HMICFRS 2018a, pp. 46-47). It also runs counter to an earlier independent review of rape investigation in London which recommended investment in specialist units (Angiolini 2015, para 21, recommendation 29). Further, a recent proposal by the British Transport Police to disband its specialist sexual offences investigation unit was withdrawn following public opposition (Farand 2016) and police in the Republic of Ireland have recently created specialist units to deal with sexual offence cases (Lally 2017).It is in this context that we proceed by setting out the mixed methodology used in this study to address some of the gaps in the current literature.

\section{Methodology}

A mixed-methods approach was adopted for this study allowing for the collection of both quantitative (case file based) and qualitative (interview) data. All potentially identifying information was removed prior to extraction and data analysis, and the research was given approval from the relevant university ethics committee. The researchers sought to examine the following questions: Do rape investigations performed by officers in a specialist unit have different trajectories through the criminal justice system in comparison to those conducted by non-specialist officers? Do specialist unit investigations provide different standards of victim support compared to the non-specialist response? How is the specialist model and non-specialist response experienced and perceived by police officers? Primarily, the research team sought to construct an extensive quantitative database containing 
detailed information on the progression and outcomes of a large number of rape (including attempted rape) investigations conducted by Avon and Somerset constabulary in 2 separate calendar years. Such an approach of 'reconstructing' investigations via this method has been successfully used in many studies that have focused on rape investigations in England and Wales over the last twenty years (e.g. Kelly et al. 2005, Feist et al. 2007, Burton et al. 2012), though has not been used previously to examine and contrast specialist vs. non-specialist data. In addition, in-depth interviews were conducted with nine serving police officers of various ranks, all of whom had experience of working in a non-specialist policing environment, and most of whom (seven) had worked or were working in the Bluestone unit. These interviews provided important insights into the workings of both approaches to rape investigation, as well as assisting the interpretation of trends emerging in the quantitative data. Further details on both elements of this study are provided below.

\section{Quantitative data}

Prior to the data collection, Avon and Somerset constabulary provided the research team with access to its case file logs for all rapes and attempted rapes reported to Bluestone in two calendar years. This data included crimes reported by both males and females, and given Bluestone's remit, only included victims aged 14 and above at the time of report. Access was granted to a further set of case files featuring non-specialist police investigations that took place in the same time period. Through a process of reading and coding the file data, the research team constructed a quantitative database in the form of an excel spreadsheet, and subsequently performed an analysis of the data using statistical software packages in both excel and SPSS. In coding the data, binary variables were constructed to denote the presence or absence of a case characteristic. For example, if a victim mental health concern could be identified in the case file data, this would subsequently be represented by coding ' 1 ' in the explanatory variable for 'victim mental health issue'. If this factor was not present, then a ' 0 ' would be entered instead. The construction of the database involved collecting detailed information on both victim and suspect demographics, case characteristics and other factors that the previous literature has identified as having an impact upon case progression (e.g. various forms of vulnerability, time between offence and report amongst others). All were converted into the binary coding framework. The team also gathered case narratives that lay outside of the framework to aid interpretation of the 
quantitative data. Once all case files had been coded, the team were able to establish key demographic features between a Bluestone (1) and a comparator (0) sample, as well as descriptive 'performance' (i.e. attrition, victim care, case outcomes) profiles for both groups. In order to assess whether some of the differences in outcomes were significant, Pearson's chi square tests of association were used to assess paired observations such as whether victims dealt with under the Bluestone model and the comparator group differed in the frequency with which they were referred to victim support. These statistical tests were conducted through contingency table functions. Where the outcomes of testing delivered chi square probabilities of .05 or less, they are referred to in this paper as 'statistically significant' and presented as ' $\mathrm{P}<0.05^{\prime}$ accordingly. Results that did not meet the .05 threshold are not reported as 'significant' in this study, though some of the 'nonsignificant' results feature prominently in our discussion, with associated caveats.

A key challenge for this study lay in establishing an appropriate comparator (i.e. nonBluestone) sample of rape investigations. Bluestone team investigations were confined to central Bristol and establishing an identical 'like-for-like' comparator that mirrored the characteristics of this urban area was not possible. The comparator sample was comprised of rape investigations in an anonymous non-specialist policing area. As a result, the Bluestone investigations contained a range of case types that were not present in the comparator sample that in this instance, were specific to the inner-city environment. These included reports made in the context of sex work/on-street prostitution (Bluestone $\mathrm{N}=38$, Comparator $\mathrm{N}=0$ ) and from victims experiencing homelessness (Bluestone $\mathrm{N}=22$, Comparator $\mathrm{N}=0$ ). Furthermore, the comparator investigations featured 7 cases involving young children that fell outside the remit of Bluestone, as well as far fewer cases where no suspect could be identified which impacted upon the ability to proceed beyond the report stage. Such cases reflect the challenges inherent to police investigations, and are undoubtedly crucial to consider in academic research, not least because they allow a more robust examination of particular forms of victimisation, vulnerability and related justice issues. However, some of the comparative analysis in this study necessitated the exclusion of these cases in order to facilitate a better understanding of relative performance (specifically, when addressing the case attrition data). The sample adjustments also allowed for the control of the difference in crime recording errors between the two sets of 
investigations (discussed further below). Without these adjustments, the comparator sample becomes simply too different in composition. The impact of the sample adjustments is detailed in Figure 1 below.

Figure 1

Bluestone and comparator data adjustments

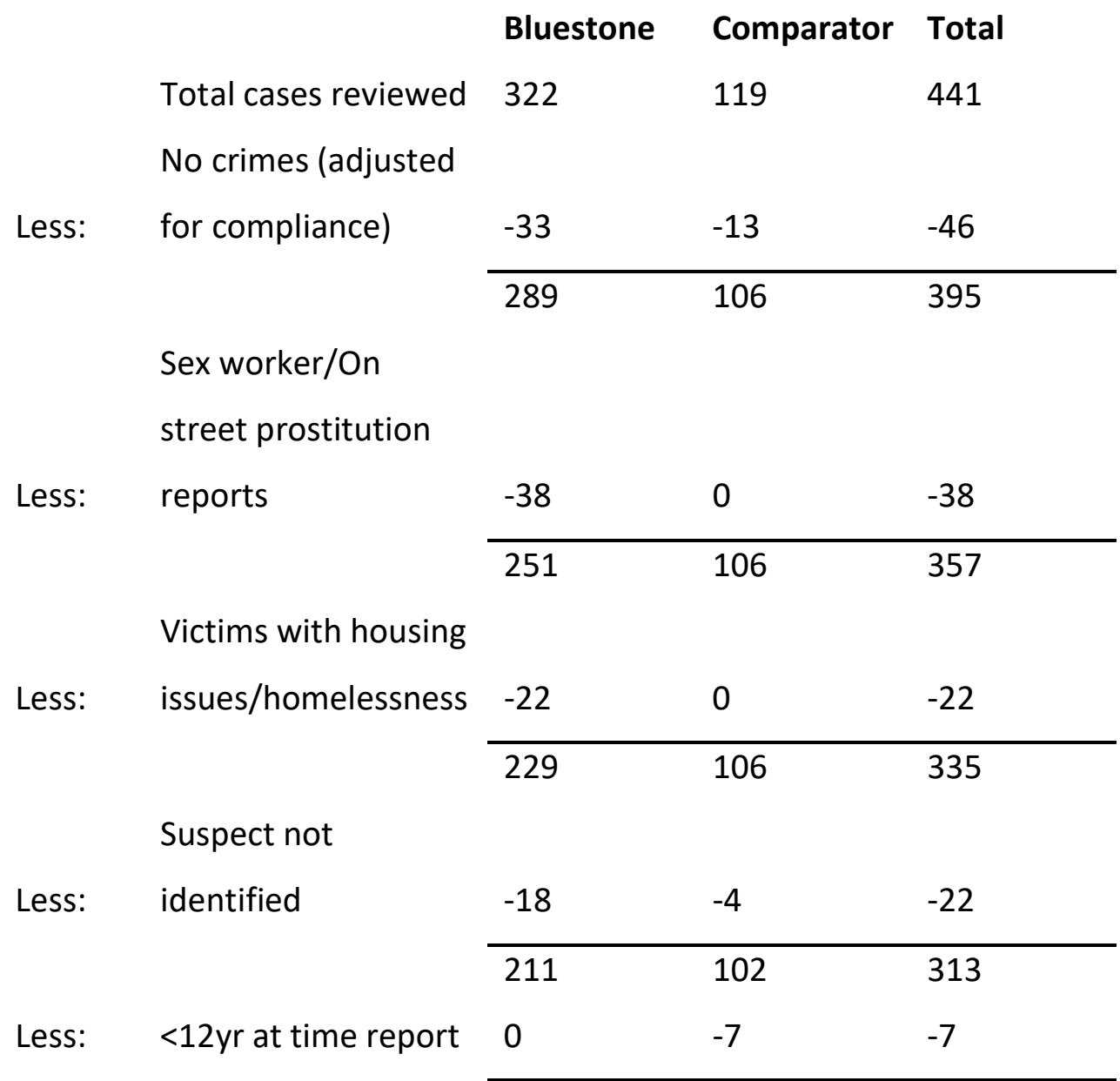

Cases compared: $\quad 211$

95

306 
This article makes reference to research findings from both the total and adjusted samples and care has been taken to signpost this accordingly throughout. Although a quantitative, case file analysis is generally regarded as a valuable method in understanding the trajectory of crime reports through the criminal justice system, there are a range of limitations that need to be acknowledged. Firstly, although using electronic recording systems tend to promote consistency of format, researchers remain dependent on the quality of information recorded in the case files, as well as individual officer recording practices. It might also be the case that certain police (in)actions are not recorded and as such, case files may not be a complete record of the investigative process (Burton et al. 2012). Second, the description and characterisation of evidence might be dependent on an individual officer's view of that evidence. This might be problematic where such an assessment is based on incomplete evidence, mistaken beliefs or unwarranted assumptions. Finally the views of victims concerning the quality of the police response is normally missing from case files, and requires additional data to give voice to this important perspective

\section{Qualitative Data}

Using a snowball method, nine officers with experience of working in both specialist and non-specialist environments were identified and interviewed for the purposes of this research. The nine officers were comprised of three SAIT officers and six detectives, and were interviewed using a semi structured interview method themed around the following areas: experience of rape investigation, perception of the specialised environment, decision making, interaction with victims and provision of victim support, victim vulnerability and relationships with partners and support agencies. An interview guide was developed to ensure consistency of approach between those conducting the interviews. All of the interviews were conducted face-to-face by members of the research team, and all occurred on police premises, lasting on average an hour. The interviews were recorded before being transcribed and coded using an inductive approach to thematic analysis (Bryman and Burgess 1994). In performing this analysis, the research team were guided by Braun and Clarke's (2006) six phase approach; specifically that of 'familiarising' with the data, generating initial codes, searching for themes, reviewing themes, defining and naming themes, and producing the report (which in this case, included linking it to the quantitative data). This process, though time consuming, was considered vital in producing a credible 
and trustworthy analysis via the thematic method (Nowell et al. 2017). Though data was collected by the broader research team, the process of familiarising and coding was performed by two project leads who worked through the entire data set concurrently. During this stage of the project, meetings were held on a weekly basis to discuss 'draft' themes emerging from the transcripts. Both project leads worked independently across each transcript, before agreeing the final themes used in the analysis. Given the need for brevity, and the small number of interviews, three main themes were identified for the purposes of this paper: 'the right people', 'case complexity' and 'team working'. Interview excerpts are also used to support and contextualise the attrition data further in this paper. Key decisions and the content of meetings between the project leads were recorded, establishing an audit trail to accompany the development of the analysis.

\section{Working in a specialist rape investigation unit: police perspectives}

The interview data offer an insight into officer perceptions of specialist and non-specialist policing in rape cases. However, the number of interviewees is small (9), so it cannot be assumed that they reflect the views of all officers. The existing literature on police attitudes to rape is quite limited with much of it focusing on officers' belief in rape myths and victim blaming (Sleath and Bull 2017). A number of studies have found that the training of officers, including those who work in specialist roles with victims of rape, such as SAIT officers, has only limited or no impact on officers' belief in rape myths or victim blaming (Lonsway et al. 2001, Sleath and Bull 2012, Hines and Murphy 2017), while others have found a beneficial impact (Darwinkel et al. 2013, Murphy and Hines 2018). The current study data differ significantly from this earlier research because the interviews had a different focus: the experiences and views of officers working in specialist and non-specialist contexts, rather than a narrow focus on rape myths and victim blaming. Three main themes emerged from the interview data and are set out below.

Theme one: the right people

The interview data provides useful insights into the nature of team working in the Bluestone unit, along with the importance of key skills, knowledge and commitment to rape case investigation. A number of interviewees commented on the importance of key knowledge and skills in rape investigations. For example: 
'Bluestone was [about] having officers there who were interested, passionate and motivated around rape investigation. Having the skill set and knowledge around rape investigations, around the psychology of the victim, the psychology of the offender and ... the different ways that victims present' (Interview 7).

Several officers also made comparative claims based on their experience of working in generalist, usually CID investigative contexts. One interviewee made reference to Bluestone as having motivated officers who 'wanted to be on there' and argued some non-specialist CID officers, with whom he had previously worked, were 'a bit frightened' of rape cases (interview 2). Another described some CID officers as 'not being keen' on rape investigations (interview 6). By contrast, a Bluestone detective linked the voluntary recruitment of Bluestone officers with professionalism and motivation:

You've got ... volunteers pretty much to work in [sexual offence] work so you've got that enthusiasm and you can get that professional outlook from the word go really ... [In CID] you've got people "oh, I don't want to deal with that"... So you haven't got that level of enthusiasm ... you know, dedication ... (Interview 9).

The reluctance of some individual CID officers to investigate rape cases - described by Interviewee 3 as 'dead wood' - is an illustration of one of the ways in which several interviewees distinguished their experience of working in the Bluestone unit from previous experience of working in generalist CID squads. Interestingly, in an Australian study of a specialist sexual offence unit it was found that the use of experienced, knowledgeable officers was perceived positively by victims: 'When victims felt reassured that the officer assigned to their case was experienced and knowledgeable in this area of work, they felt valued' (Powell and Cauchi 2013, p. 233-234). The authors of the research argued that this resulted in improved victim engagement with the investigative process, reporting and encouraged victims to recommend reporting to others (Powell and Cauchi 2013, p. 234). While skilled officers work in specialist and non-specialist environments, it is important to note that Bluestone officer perceptions of their motivation and development of crucial skills derived from investigative specialism (see below), dovetails with the views of victims found by Powell and Cauchi. 
Theme two: case complexity

The creation of the Bluestone unit was seen as important because rape was viewed as a 'specialist offence' (Interviewee 1) involving complex victim circumstances and investigative challenges. A SAIT officer observed:

Rape is a very different investigative crime and if you get people that want to investigate that it makes such a difference because you get people that understand rape victims and ... want to utilise the resources ... including SAIT officers (Interview 4).

It has been suggested that there is need for a specialist response to rape cases because they have characteristics, including manipulative, predatory offenders, victims with complex needs, trauma and vulnerabilities, that require highly-skilled officers and dedicated resources (Stern 2010, Pettitt et al. 2013, Angiolini 2015). Bluestone officers also pointed to the importance of specialism in the acquiring of key skills and knowledge. For example:

You just think of things and use that the next time and build up that bank of knowledge and what you know will help with the case that you might not always pick up on if you are dealing with lots of different types of offences (Interview 2).

You are aware of the processes ... and I think that's helped in terms of when you ... do end up in court you actually know what you are talking about ... (Interview 6).

In earlier domestic research, officers suggested specialism improved investigative expertise (Westmarland et al. 2012) and a recent HMICFRS report observed that sexual offence 'investigations require officers with the highest levels of skills and competence, which take the longest to acquire' (HMICFRS 2017, p. 52). Findings from the wider literature, combined with this study's interview data suggest that specialist investigative units provide an important means of developing the expertise necessary to address the challenges of rape case investigation. The next theme adds another important layer to understand the nature and importance of specialist unit working.

Theme three: team working

The creation of the Bluestone unit was intended to encourage referrals to specialist support agencies and a 'joint team approach' between detectives, Sexual Assault Investigation Trained (SAIT) officers and support services to ensure victim co-operation and reduce the 
likelihood of withdrawal (Avon and Somerset Constabulary 2011, p. 10). Interviewees identified four aspects to this team working approach. First, there was a sense of common purpose:

'we'll talk [about cases] and we're really close because it's quite a small unit, everyone's you know working towards the same thing so that's a real benefit' (Interview 3).

Second, support and efficient communication was facilitated by the co-location of detectives and SAIT officers. Earlier research has suggested that when specialist officers work in the same physical space it facilitates communication (van Staden and Lawrence 2010, p. 4, Powell and Wright 2011-2012). Several interviewees concurred and reported that co-location also assisted in facilitating team working and mutual assistance. For example, a SAIT officer stated:

'Having the investigator on hand is so much better than trying to track them down with phone calls and emails and what have you. So they're in the office you can track them down and you work as a team ...' (Interview 4).

A detective added:

We would all help each other, you would have the primary investigator ... so you would know if you were the officer in the case. But then everyone would really help you to get those priority, quick time inquiries done (Interview 2).

Third, the idea of mutual assistance inevitably involves placing confidence and value in the skills and abilities of others. Earlier Home Office research involving officers who worked in a specialist unit reported that its creation improved interalia, officer confidence in dealing with sexual offence cases and 'increased confidence in each other's ability' (van Staden and Lawrence 2010, pp. 12-14). By contrast, the two non-specialist unit SAIT officer interviewees pointed to a degree of isolation in their working lives:

..we're sat with CID so we're sort of more of a team of work people but they're not necessarily dealing with the same work as us. So it's not a team as in work team ... (Interview 8)

CID obviously have got their teams and somebody will come back into the office and they've done their bit and someone else, they'll go 'is there anything else I can help you with before 
we go?' ... I haven't got that. And that's [when] sometimes I think 'oh that would be nice if I had someone to' ... (Interview 5)

These findings are similar to those of McMillan who interviewed SAIT officers working with CID detectives. She found some SAIT officers reporting that they were expected to 'go it alone' and were not always valued or supported (McMillan 2015, p. 630). This can be contrasted with the Bluestone SAIT officers who emphasised the team working approach: 'I think it's nice working with someone who knows the same job, maybe knows the same victim so that they understand the pressures that are maybe put on you by that victim or maybe the job or whatever ... So you're sharing the load a little bit' (Interview 4).

In terms of the perceived value of SAIT officers, a detective contrasted Bluestone with her previous experience of working in CID:

'Outside of Bluestone there was very much a feeling of "I don't need a SAIT officer I can do this myself" or "we won't bother getting them in because they are too far away ..." (Interview 7).

Bluestone detectives also emphasised the crucial role of SAIT officers:

[SAIT officers] were very helpful because you could get on with the investigation knowing the victims were being looked after and being kept up to date ... they would maintain that rapport and that was really good we could just carry on and concentrate on the investigative side and the suspects as well (Interview 2).

[W] [eally benefited from the SAIT officers taking some of the pressure off us because dealing with the victim, updating them on, making sure they are supported is a big job (Interview 6).

The importance of team working in the context of demanding and complex investigations led the Stern Review to conclude that the 'police should not have to work on their own to deal with rape complainants' (Stern 2010, p. 118). The willingness of officers to work with other agencies is the fourth team working element referenced by Bluestone officers and supports earlier findings from an Australian study of specialist unit working practices (Powell and Wright 2011-2012). A Bluestone detective noted: 
The SAIT officers, they were fantastic, working closely with the Bridge [Bristol-based Sexual Assault Referral Centre], that really helped. Good relationship with partner agencies ... for me [the] One25 project [an agency supporting women involved in street prostitution] were fantastic (Interview 1).

The value placed on the role of SAIT officers is reflected in the fact that their allocation in Bluestone investigations was the norm, unlike the comparator, which will be discussed later in this article. Interestingly, an officer observed that his personal approach to rape investigation and the role of team working had changed when serving in the Bluestone unit:

I think what Bluestone taught me is effective partnership is just key. Looking at what your objective is and then just looking at the easiest way to get there by using partner agencies and just being really aware of that. But when I first joined the police, I thought it was the police's job alone whereas now there are so many people that can help and assist (Interview 1).

The interview data differ markedly from contemporary descriptions of police attitudes, which are said to be reliant on myths, victim blaming, and the 'real rape' stereotype (Sleath and Bull 2017).4 In the current study, however, the interviewees did not exhibit these attitudes. This might reflect the nature of the interview questions which focused on issues such as victim care, vulnerability, team working and rape case investigation. Given the number of interviewees, it cannot be assumed that these findings are generalisable to all Bluestone officers. Further, the interview findings do not mean that officers did not hold negative attitudes of some sort, or that such attitudes did not impact on rape case decisionmaking. By the same token, it should not be assumed that negative attitudes, where they exist, inevitably influence professional behaviour (Barrett and Hamilton-Giachritsis 2013).

\section{Case file data}

\section{Sample characteristics}

93.8\% of Bluestone cases and $90.5 \%$ of comparator cases involved a female victim. $16.4 \%$ of Bluestone cases involved victims with a Black and Minority Ethnic (BME) identity compared with $7.0 \%$ in the comparator, thus reflecting the more diverse nature of a city-centre environment such as the Bluestone area (see Figure 2 below). In terms of age, 91.5\% of 
Bluestone cases involved victims who were 16 years or older at the time of the report, compared to $80.4 \%$ of comparator cases; a difference that reflects the Bluestone remit of investigating cases involving a victim of 14 years or older. Those aged between 16 and 25 made up the largest single group of victims in both the Bluestone investigations (48.0\%) and comparator sample (37.0\%). The age profile of the victims reflects that found in other studies that suggest young adult females are most at risk of rape (Ministry of Justice et al. 2013 , p. 14). Bluestone had proportionally fewer cases involving intimates than the comparator (63.8\% vs. $76.1 \%)$; more stranger rapes (10.1\% vs. $4.3 \%)$ and more acquaintance rapes (26.1\% vs. $19.6 \%)$. One of the more striking features of the data was the number of cases involving victims with multiple vulnerabilities. In defining vulnerability for the purposes of this research, we adopt a broad understanding of vulnerability in line with that used in previous research on rape (Stanko and Williams 2009), and define it to include exposure to economic, social, physical and emotional harm prior to, during and after rape ${ }^{2}$. Such cases have been shown to have lower rates of case progression in earlier research (Stanko and Williams 2009, Hester and Walker 2017).

\footnotetext{
2 One of the reasons for using this broad definition lies in the frequent difficulty found in distinguishing between preexisting vulnerability, and post-victimisation vulnerability from the available case file data.
} 
Figure 2

Case file comparisons- key characteristics (adjusted sample)

\begin{tabular}{|c|c|c|}
\multicolumn{2}{|c}{ Bluestone } & Comparator \\
\hline \multicolumn{2}{|c|}{ Victim } & $\%$ \\
Female & 93.8 & 90.5 \\
White & 83.5 & 92.9 \\
BME & 16.4 & 7.0 \\
Age >16 & 91.5 & 80.4 \\
Aged between 16 and 25 & 48.0 & 37.0 \\
\hline Type of Relationship & & 76.1 \\
Intimates & 63.8 & 4.3 \\
Strangers & 10.1 & 19.6 \\
\hline Acquaintances & 26.1 & 93.6 \\
\hline Vulnerabilities identified & & 43.6 \\
1 or more vulnerabilities & 96.6 & 13.8 \\
\hline 2 or more vulnerabilities & 54.2 & \\
3 or more vulnerabilities & 18.1 & \\
\hline
\end{tabular}

Although both data sets contained very high numbers of victims deemed to be vulnerable in some way (96.6\% Bluestone vs. 93.6\% comparator), more Bluestone victims were identified as having two or more vulnerabilities than in comparator cases ( $54.2 \%$ vs. $43.6 \%)$, as well as three or more vulnerabilities (18.1\% vs. 13.8). The unadjusted data shows a much larger proportion of victims with multiple vulnerabilities in the Bluestone sample. ${ }^{3}$ The impact of multiple vulnerabilities is discussed further in the sections that follow.

\footnotetext{
${ }^{3}$ When considering the Bluestone and comparator samples as a whole, and without the adjustments identified in Figure 1, the differences in the numbers of vulnerable victims was far more pronounced. On an unadjusted
} 


\section{Case attrition}

Attrition is the process whereby cases 'drop out' of the criminal justice system at 'one of many points of exit' (Lea et al. 2003, p. 583, Brown et al. 2007, p. 355). The main exit points in rape cases are at the police investigative, CPS referral, charging and court stages.

Significant levels of attrition exist across various serious crimes (Burton et al. 2012, p. 7) with the main point of attrition in rape cases being at the investigative stage (Lea et al. 2003, Kelly et al. 2005, Brown et al. 2007, Feist et al. 2007, Hester 2013, Hohl and Stanko 2015). There are numerous factors that may have an influence over the progression of cases through the criminal justice process. These include the absence/presence of corroborative evidence (Feist et al. 2007, p. 89, Hester 2013, p. 18), victim withdrawal, the exercise of police and prosecutorial discretion, the impact of 'schematic processing' where myths or stereotypes may influence professional decision making (Hohl and Stanko 2015, p. 328), guilty pleas, and the standard and burden of proof in criminal cases (Bryden and Lengnick 1997). Both the Bluestone and comparator investigations shared a similar profile of attrition with the steepest point of drop out being at the investigative stage with $64.4 \%$ of Bluestone cases and $68.4 \%$ of comparator cases falling out at some point prior to charge. A major contributing factor to this steep decline was the removal of initially recorded offences under the Home Office Counting Rules (Home Office 2017). The rules exist to ensure police officers appropriately record reported crime notifiable to the Home Office. The HOCR set out several grounds in which recorded offences can be 'cancelled' or 'transferred' (until April 2015 this was known as 'no-criming') and thus be removed from the recorded crime count ${ }^{4}$. The police service has been criticised for poor crime recording practices, inaccurate recording and the unwarranted dismissal of allegations as untrue (HMIC 2014). While problems concerning reporting accuracy have been consistently reported (HMIC 2014, House of Commons 2014, Public Administration Select Committee 2014, HMICFRS 2016b)

\footnotetext{
basis, Bluestone had more cases featuring victims with two or more vulnerabilities compared to the comparator $(60.0 \%$ vs. $40.0 \%)$, Bluestone also had more cases featuring victims with three or more vulnerabilities $(23.0 \%$ vs. $12.0 \%)$.

${ }^{4}$ The previous reference to 'no-criming' of cases has been replaced with the use of 'transfer' and 'cancel' which are divided into four categories. Transferred cases are those that took place in another force area. Cancelled cases are those where the crime was recorded in error, constitutes part of an already recorded crime, or where there is 'additional verifiable information' (AVI) that no crime occurred.
} 
evidence suggests improvement in some force areas (HMICFRS 2016a, 2016b, 2016c), but that problems in other force areas remain (HMICFRS 2018b). The current research sought to examine the nature and accuracy of crime recording by Bluestone and comparator area in light of the HOCR. Bluestone transferred or cancelled proportionally fewer cases than the comparator area in the two study years examined (18.6\% vs. $26.5 \%$; $9 \%$ vs. $11.3 \%)$. Overall, Bluestone officers recorded rape allegations in compliance with the HOCR more often than in the comparator area ( $77.5 \%$ vs. $64.7 \%)$. In the Bluestone case files, there was evidence that some officers misunderstood the HOCR or wrongly equated evidential uncertainty and complexity with grounds for cancellation. In such circumstances, the HOCR state that the 'rape must remain recorded' (Home Office 2017, section C). Similar errors were made in some comparator cases. There were also problems that were unique to the comparator cases. In one case for example, a recorded allegation was cancelled on the ground of there being 'additional verifiable information' that no crime occurred because the victim was not actively engaged with the investigation. Decision-making that equates lack of engagement with falsity is not unique to this study (HMIC 2014, pp. 77-78) and suggests a poor understanding of why victims may not engage, including trauma, victim perceptions of the police and fear. In another comparator case, a senior officer explicitly acknowledged they were defying the HOCR when cancelling a recorded rape allegation.

Figure 3 shows the general attrition profile of Bluestone and comparator cases, which indicate several points of attrition: rate of arrest ( $65.8 \%$ vs. $87.3 \%)$; charge (35.5\% vs. $31.5 \%)$; reached court ( $29.8 \%$ vs. $27.3 \%)$; conviction of any offence ( $15.6 \%$ vs. $22.1 \%)$; conviction of rape $(9.4 \%$ vs. $11.5 \%)$. The data should be read with care as there are contextual issues that are important to understand when interpreting the progression data. For example, one of the most striking differences between Bluestone and the comparator is the lower arrest rate in Bluestone cases $(65.8 \%$ vs. $87.3 \%, \mathrm{P}<0.05)$. One explanation for this difference is that as a matter of policy, the Bluestone officers were encouraged to invite suspects to attend interviews on a voluntary basis. One Bluestone detective observed that under the Police and Criminal Evidence Act 1984 Codes of Practice 'there needs to be a necessity for arrest ... [if] there's no necessity to arrest there should be voluntary interviewing'. The detective went on to explain that arrest was more likely in 'live' case 
investigation or where there was a 'need to search, secure evidence or if there was a danger evidence would be destroyed' (Interview 1).

Figure 3

Attrition profiles for Bluestone and the comparator

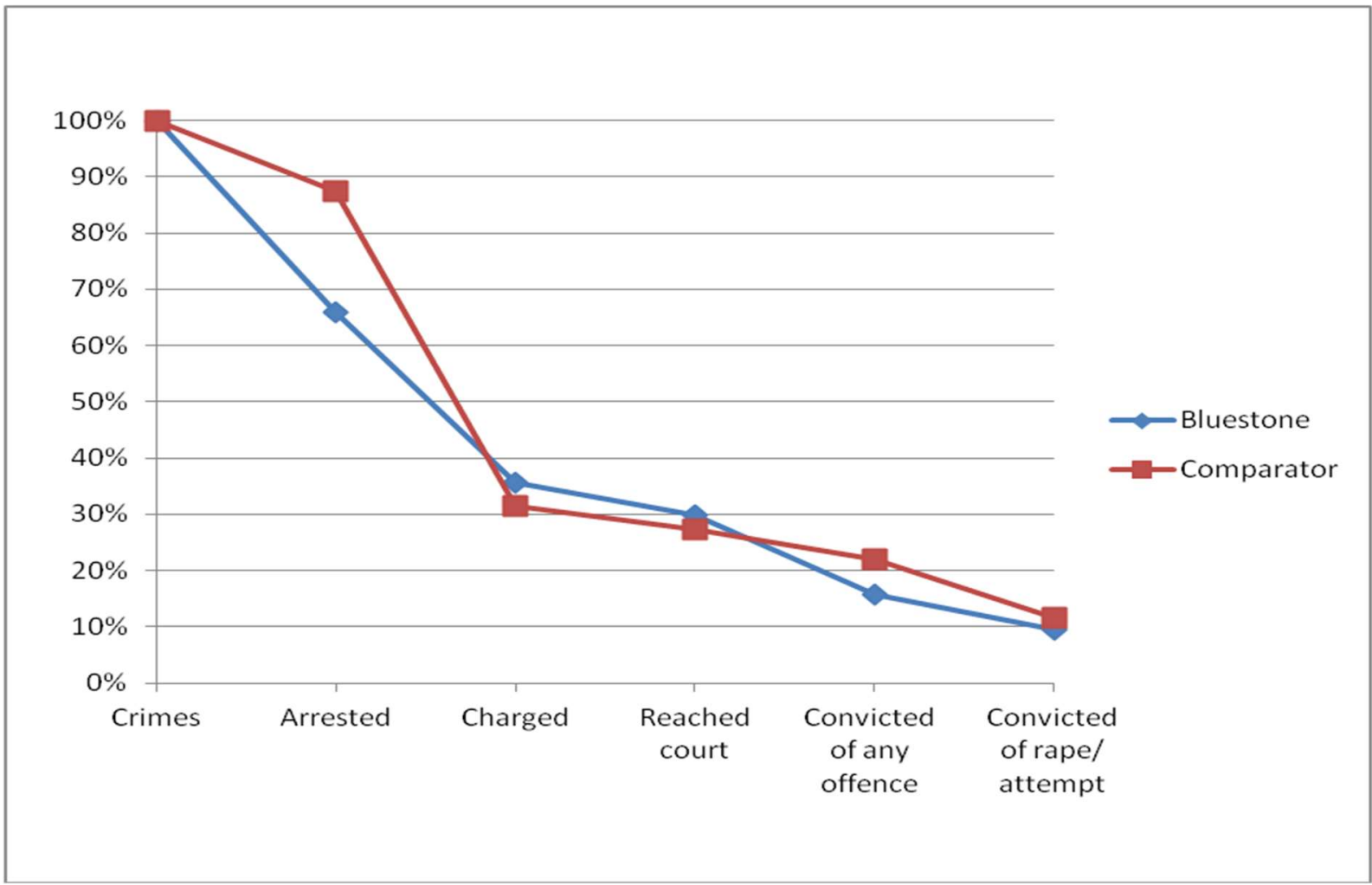

A minor contribution to the attrition rate in both samples relates to the small number of victims who did not want a formal police investigation (3\% Bluestone vs. $2 \%$ comparator). Under traditional performance metrics of arrest, charge and conviction, such cases would have no discernible outcome and could be interpreted as a criminal justice failure. Yet, the victim may regard his or her interaction with police positively. Robinson notes that in some cases, successful engagement with the criminal justice process from a victim's point of view may simply constitute making a formal statement (Robinson 2009, p. 31). This may be representative of what McGlynn and Westmarland refer to as 'kaleidoscope justice' - the 
idea that victims' perceptions of justice are dynamic, evolving and personal (McGlynn and Westmarland 2018). In the case files, victims who did not want a formal investigation included those who wanted to provide intelligence to the police or wanted officers to confirm the location of a suspect in another country. These met the wishes of victims at that time and provide examples of the way in which victim engagement with the criminal justice process is nuanced and subject to the wishes of individual victims.

The Bluestone investigations exhibited a higher charging rate than the comparator investigations ( $35.5 \%$ vs. $31.5 \%$ ), and a somewhat higher proportion of Bluestone cases also reached court ( $29.8 \%$ vs. $27.3 \%$ ) despite Bluestone having a higher concentration of victims with multiple vulnerabilities. The challenges these cases pose for the investigative process, including victim engagement and higher rates of withdrawal are significant. ${ }^{5}$ For those cases involving victims identified with one vulnerability, Bluestone was able to achieve a greater rate of retention evidenced by higher rates of charge $(44.9 \% n=40$ vs. $38.2 \% n=18)$ and higher proportions of cases reaching court $(38.2 \% n=34$ vs. $31.9 \% n=15)$. Bluestone also had a higher charging rate in cases involving victims identified with two vulnerabilities $(32.8 \% n=25$ vs. $25.0 \% n=7)$ and a somewhat higher reached court rate $(27.6 \% n=21$ vs. $25.0 \% n=7) .{ }^{6}$ One possible explanation for this is the emphasis that Bluestone placed on victim care, including greater levels of SAIT officer involvement and a higher proportion of victims being referred to an ISVA ${ }^{7}$. The relationship between victim withdrawal and support referrals is discussed in more detail later in this paper.

Although good police work in terms of evidence collection and victim care may influence the prospect of cases reaching the trial stage, conviction rates at trial cannot be considered a robust measure of police performance given the range of factors in operation at that stage of the criminal justice process. For this reason, it cannot be assumed that the lower rate of conviction in Bluestone rape cases (9.4\% vs. $11.5 \%)$ and more noticeable difference in convictions for any offence ( $15.6 \%$ vs. $22.1 \%)$ resulted from comparatively poor practice by

\footnotetext{
${ }^{5}$ Linear regression analysis performed on a combined sample of all Bluestone and comparator crimed cases $(n=376)$ revealed that those with three or more victim vulnerabilities increased the odds of a case being classified as 'No Further Action' by $240 \%(p<0.05)$. Victim withdrawal rates in the combined 3+-vulnerability group were $40.7 \%$.

${ }^{6}$ Due to the very small number of comparator cases it is not possible to do a comparison involving cases with three or more victim vulnerabilities
} 
Bluestone officers. Indeed, factors that help explain the differences between the two sets of investigations were identified. For instance, of cases that reached court, $11.6 \%$ of Bluestone defendants pleaded guilty to rape and $6.9 \%$ pleaded guilty to other offences. For the comparator, these figures are $31.2 \%$ and $6.2 \%$ respectively. Such differences are important and may well reflect the differing age profiles in the two samples. In the Bluestone sample, of rape cases that reached court, $7.9 \%$ of victims were aged between 13 and 15 at the time of reporting. This figure was almost double (15.3\%) for the comparator. Given the legal age of consent (16), one might expect to see a higher guilty plea rate in the comparator. Indeed, $60 \%$ of the guilty pleas made in the comparator sample were made in cases relating to the rape of a child. A second potential explanation for the lower Bluestone conviction rate is the higher proportion of cases involving victims with multiple vulnerabilities. While Bluestone was somewhat more successful than the comparator in keeping such cases in the process, the higher the number of victim vulnerabilities identified in a case, the more pronounced the overall attrition rate.

Figure 4 illustrates that in several measures, Bluestone had more favourable case progression and outcomes in 'live' rape cases (those reported within seven days of the alleged offence and with a greater potential for evidence collection) than the comparator. This may be linked to the higher proportion of stranger rape cases in the Bluestone 'live' cases compared with the comparator area. $19.3 \%$ of Bluestone 'live' cases and $9.0 \%$ of comparator cases were stranger rape cases. Such cases have been shown to result in a higher rate of conviction than acquaintance and intimate rape cases in this, and previous research (Feist et al. 2007, Hester and Walker 2017). The Bluestone 'live' stranger rape cases had an overall rape conviction rate of $35.2 \%$ and, of cases that reached trial, $71.4 \%$ included evidence of victim injury. In both sets of investigations, the arrest rate was higher in 'live' cases compared to cases generally, perhaps reflecting the need to secure scenes of crime and maximise the opportunity for gathering forensic evidence. The gap between Bluestone and comparator arrest rates also narrowed. As with the general attrition profile in Figure 3, Bluestone's use of voluntary suspect attendance may have contributed to a lower arrest rate in 'live' case investigations compared to that found in the comparator case file data. 
Figure 4

Attrition profiles for 'live' cases, Bluestone and Comparator

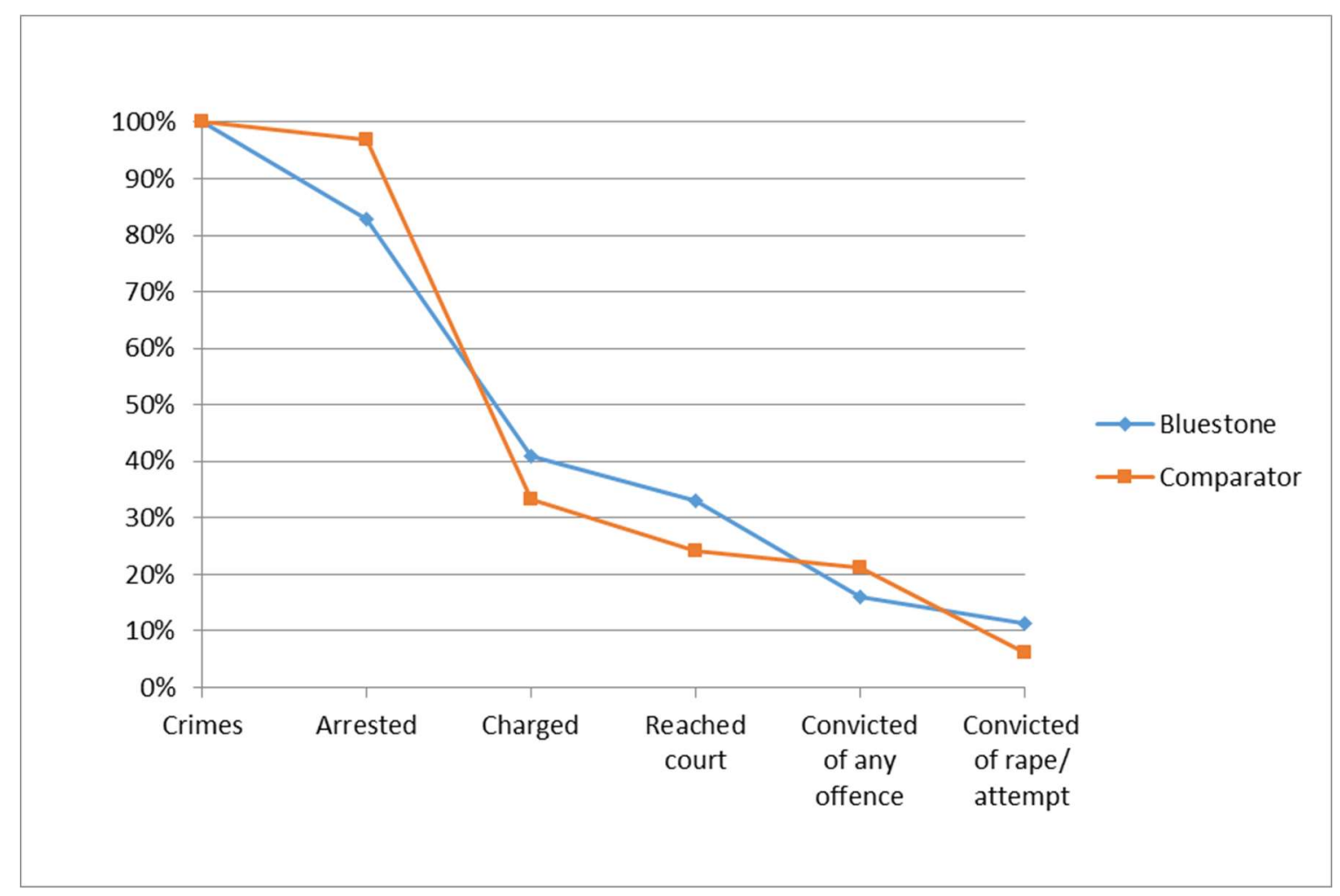

Victim withdrawal has been shown to be an important contributor to case attrition that can occur at any point in the criminal justice process (Feist et al. 2007, Hohl and Stanko 2015). Previous research has identified many reasons for victim withdrawal, including: anxieties about the criminal justice process, a victim wanting to move on and pressure to withdraw by third parties (Kelly et al. 2005, pp. 55-56). The current study identified similar reasons for withdrawal, with the most common in the Bluestone cases being: not wishing to go through the investigative/court process (28\%), wanting to move on (14\%), health or mental health concerns (11\%) and refusal to cooperate with the police (9\%). Despite the enhanced performance of Bluestone across several points of attrition, Bluestone still had a higher rate of withdrawal compared to the comparator (33.0\% vs. $21.2 \%$ ). One potential explanation for the higher rate of withdrawal is that Bluestone, as previously noted, had more cases involving multiple vulnerabilities and these were shown to have a progressively higher rate 
of withdrawal. In Bluestone cases, withdrawal rates for victims with three or more vulnerabilities was $47 \%$, compared to those with two vulnerabilities (37\%), one vulnerability (31\%) and no vulnerabilities (14\%).

\section{Victim care}

Improving victim care and welfare was a key aim of establishing the Bluestone unit (Avon and Somerset Constabulary 2011). In the interviews, several officers commented negatively on the pre-Bluestone approach to victim care. For example, one detective argued that a 'large part' of victim withdrawal prior to Bluestone 'was due to lack of support, or lack of information, lack of updates ... ' (Interview 1). Previous research suggests that using the expertise and support of ISVAs may improve certain criminal justice-related outcomes including 'enabling victims to give their evidence in court, reducing retractions and obtaining convictions' (Robinson 2009, p. 31). However, such findings were based on impressionistic assessments by interviewees, and as Robinson observes it was 'difficult to substantiate these feelings with the monitoring data available at the time of writing' (Robinson 2009, p. 31). Further, data derived from professionals, while undoubtedly important, may not match the perception of victims themselves (Campbell 2005). Previous specialist unit studies have also relied on interviewees who suggested specialism led to improvements in victim care (van Staden and Lawrence 2010, Westmarland et al. 2012). Australian research by Powell and Cauchi (2013) found that sexual assault victims viewed the response of a specialist investigation unit more favourably than a non-specialist response. The current study has sought to examine issues of victim care via police officer interviews and crucially, two quantitative measures: the allocation of SAIT officers during the investigative process and police referrals to victim support services, including ISVAs.

Sexual Assault Investigation Trained (SAIT) officers are trained to provide care and support to victims of rape, build rapport and trust, update victims on the progress of the case and act as a bridge between the victim and investigating officers (Horvath and Yexley 2012). To this point, little research has explored the work of SAIT officers (McMillan 2015). The case files showed that within Bluestone, SAIT officer allocation was the norm, with only rare exceptions. For example, in a historic rape case, the victim said that a SAIT officer was unnecessary and was happy to be contacted directly by detectives working on the case. By contrast, in the comparator there was a SAIT officer allocation in just $41.0 \%$ of cases. In 
some of these cases this appeared to be a mere paper allocation in the sense that there were no case file entries by the allocated SAIT officer or other evidence of actual SAIT officer involvement.

In Bluestone cases, SAIT officers played a pivotal role in maintaining contact with victims and persuading reluctant victims to engage with the investigative process. One detective reflected on this: 'we've dealt with cases before if it wasn't for the SAIT officer we would have lost our victims. We would have lost prosecutions. We would have dangerous offenders still out and about in public' (Interview 6). Previous interview-based research found that amongst CID detectives, victim welfare 'took second place to their view of her as a source of information' (Barrett and Hamilton-Giachritis 2013, p. 211). The authors of the study acknowledge that this finding may have resulted from the investigative role of detectives and that SAIT officers were not included, thus leaving out an important source of data regarding victim care. The Bluestone findings suggest a somewhat more fluid picture in terms of professional roles and the case files indicated that detectives sometimes played a key role in providing victim care. There were frequent case file entries detailing investigating officers' discussions concerning the welfare of victims, evidence of intervention by detectives when problems emerged and examples of detectives giving re-assurance to encourage continued cooperation with the investigation. For example, in one case, Bluestone detectives made concerted efforts to find a victim with a long history of vulnerability after a SAIT officer had been unable to contact her. The detectives found her asleep in a house while heavily intoxicated and the front door open. In the case file, a detective logged that they had ensured she was not a danger to herself, made sure nobody else was in the house and secured the property. In another case, a detective spent several hours working with a SAIT officer trying to find appropriate accommodation for a young victim. There were also examples of detectives providing information or support in order to reduce anxiety. In one case for example, a detective explained to a victim that his anonymity was legally protected for life after he expressed anxiety that he might be named in the media. One Bluestone detective discussed his learning from his time in the Bluestone unit:

'On Bluestone, I think I developed a more caring approach to victims of crime, because it was very much about supporting victims, keeping them on board, supporting them because, to get the best evidence from them and you need them to be as happy as possible and 
supported as possible so I think my time on Bluestone I learnt how important it is to keep victims happy and support victims' (Interview 1).

The role of Bluestone detectives in victim care partly resulted from the practical needs of victims, but also from a desire to maintain contact: 'I always like to keep in contact with the victims. I think it is really important that they've got, they know who the investigator is as well' (interview 3). The comparator case files also included many examples of detectives providing updates to victims and checking on relevant welfare issues. However, the far lower number of SAIT officer allocations made this a necessity. It is not possible to discern whether detectives pursuing two roles - investigative and victim support - impacted on the quality of the investigation or support offered, although one Bluestone interviewee noted how SAIT officers enabled him to effectively pursue his role: 'the pressure is taken off the [detective] to do the victim side of things and the SAIT can do that role and allows the [detective] to get on' (Interview 4).

The second measure used to assess victim support in the Bluestone and comparator cases was the number of referrals to specialist support services, including Independent Sexual Violence Advisors (ISVAs). The Stern Review recommended that ISVAs be 'an intrinsic part of the way rape victims are dealt with, as the service that enables the rest to operate effectively and a crucial part of the way in which the State fulfils its obligations to victims of violence' (Stern 2010). ISVAs provide professional support to victims of sexual violence, including: emotional support, help and advice of a practical nature; help and information throughout criminal justice proceedings, and have been shown to improve multi-agency working to support victims (Robinson 2009, Hester and Lilley 2015). Within the criminal justice system, ISVAs act as advocates for the victim, conveying the victim's views or wishes to criminal justice agencies and accompanying and supporting them throughout the process. In previous research, Hester and Lilley found that ISVA support was 'deemed crucial [by victims] to their progression through the criminal justice system' (Hester and Lilley 2015, p. 12). The current research is the first to use quantitative data to examine whether ISVA support referrals reduce victim withdrawal from the criminal justice process (Figure 5). The data from the unadjusted Bluestone sample $(n=278)$ indicates that an ISVA referral was a 
crucial feature of cases that did not result in victim withdrawal $(P<0.05) .{ }^{8}$ This finding is particularly noteworthy because the unadjusted sample includes cases with victims suffering some of the most challenging personal circumstances, specifically, housing issues/homelessness and involvement in prostitution. Rates of support referral and victim withdrawal are presented comparatively below for the adjusted data.

Figure 5

Support referrals and victim withdrawal (adjusted data) ${ }^{9}$

\begin{tabular}{|c|c|c|c|c|c|c|}
\hline & \multicolumn{3}{|c|}{ Bluestone } & \multicolumn{3}{|c|}{ Comparator } \\
\hline & \multicolumn{2}{|c|}{ Support referrals } & \multirow{2}{*}{$\begin{array}{c}\text { Withdrawal } \\
\text { rate } \\
\%\end{array}$} & \multicolumn{2}{|c|}{ Support referrals } & \multirow{2}{*}{$\begin{array}{c}\text { Withdrawa } \\
\text { rate } \\
\%\end{array}$} \\
\hline & $N$ & $\%$ & & $N$ & $\%$ & \\
\hline \multicolumn{7}{|l|}{ ISVA } \\
\hline Other & 113 & $62.0 \%$ & $26.6 \%$ & 27 & $32.9 \%$ & $22.2 \%$ \\
\hline support & 42 & $23.0 \%$ & $36.5 \%$ & 37 & $45.1 \%$ & $21.6 \%$ \\
\hline Total & 155 & $85.1 \%$ & $29.3 \%$ & 64 & $78.0 \%$ & $21.8 \%$ \\
\hline No referral & 27 & $14.8 \%$ & $33.0 \%$ & 18 & $21.9 \%$ & $33.3 \%$ \\
\hline
\end{tabular}

Comparing Bluestone and the comparator, two further findings are of importance. First, in those cases where victim support was recorded, there were more support referrals in Bluestone cases than the comparator ( $85.1 \%$ vs. $78.0 \%)$. Where a referral was made, ISVA referral rates were significantly higher in Bluestone cases $(72.9 \% n=113$ vs. $42.1 \% n=27, P$ $<0.01$ ). This finding suggests that Bluestone's emphasis on victim care, along with its focus

\footnotetext{
8 The unadjusted Bluestone sample produced a $27.1 \%$ withdrawal rate when an ISVA referral was made, $42.8 \%$ with any other support referral and $50.9 \%$ with no support referral.

${ }^{9}$ Information available in 182/211 Bluestone cases, 82/95 comparator cases.
} 
on multi-agency working, meant victims were more likely to be channelled to a vital source of specialist support. It also suggests that Bluestone officers recognised the important role of ISVAs in terms of support. Further, the wider literature emphasises the importance of a 'joined up', multi-agency response to complex cases, particularly to those involving victims with multiple vulnerabilities (Pettitt et al. 2013, Angiolini 2015, Ellison 2015). Improving multi-agency working to support victims was a key objective of the Bluestone model (Avon and Somerset Constabulary 2011). One Bluestone detective contrasted Bluestone with the pre-Bluestone approach:

There is help out there for all these victims. There's [sic] numerous referrals to other agencies that will help them whereas before we probably didn't have that. They would get a phone call to say "yeah somebody has been arrested, yeah see you in court" (Interview 6).

The Bluestone case file data suggest two main reasons for officers not making an ISVA support referral. Either victims already had a history of involvement with support services and did not need an ISVA referral, or a victim did not want to have an ISVA referral. Even with the much higher referral rate, it cannot be assumed that there were not Bluestone cases where ISVA support was needed, but no referral was made. Despite this, the study has been able to establish, for the first time, that ISVA referrals have a statistically significant impact on victim withdrawal in cases of rape and provide further evidence of their value in the criminal justice process.

\section{Discussion}

Many forms of criminality, including terrorism, serious and organised crime and child abuse are commonly investigated by specialised police units to ensure that challenging investigations are dealt with by highly skilled officers. It is often argued that rape cases have unique features that point to the need for investigative specialism, victim support, specialist training and assessment of officer performance (National Policing Improvement Agency 2010).12 Further, it is evident that many rape cases feature complex investigative challenges that can be explained in a number of ways. First, rape is a crime that can be difficult to prove to the standard required in the criminal courts given that many rapes are not witnessed and leave no physical, forensic or other corroborative evidence (Feist et al. 2007, pp. 29-31). Second, the absence of corroborative evidence of non-consent 
contributes to what the Stern Review report noted as being the 'unique difficulties' faced by police that are 'not present when dealing with other crimes' (Stern 2010, p. 45, 71. See also: Angiolini 2015, para 434). In her review of rape case treatment in London, Angiolini acknowledged the complexity of rape case investigations, including those involving victims with complex vulnerabilities. She argued that rape cases pose 'unique challenges, which in their variety and complexity often far exceed the difficulties encountered in investigating other offences' (Angiolini 2015, para. 30). It is the complex nature of these cases that has led various study authors to emphasise the importance of investigative specialism in cases of rape and serious sexual assault (Stern 2010, van Staden and Lawrence 2010, Powell and Cauchi 2013, Angiolini 2015).

Third, rape cases require a policing response in which officers understand these complexities and the needs of victims who are vulnerable, traumatised and may struggle to engage with the investigative process. As previously noted, some of the Bluestone officers interviewed acknowledged the depth of knowledge and skills they gained through specialisation, contrasting that with their experience of non-specialist rape investigations. One detective observed that prior to the existence of Bluestone: 'officer knowledge wasn't there because you are dealing with so many other things as well' (Interview 6).

The fourth element that arguably sets many rape cases apart from other offences is the support victims require after reporting to the police. One of the study interviewees noted a shift in his own views regarding victim care after he joined the Bluestone unit:

[Prior to Bluestone] I treated those victims as the same as a GBH victim or the same as a fraud victim. It's not the same. I mean crime effects people differently, but in my experience a victim of rape it doesn't get much worse than rape in terms of offences that really affects the victim. So, they need that extra level of support (Interview 1).

As noted earlier in this paper, a further characteristic of rape cases found in this and other studies (Angiolini 2015, pp. 79-80, Kelly et al. 2005, p. 62) are the number of victims with multiple vulnerabilities and complex personal circumstances who require significant levels of care and ongoing support. The higher rate of Bluestone SAIT officer allocation and ISVA referrals, compared to the comparator, provides evidence of the way in which Bluestone, with its focus on high quality victim care, supported victims who experience complex 
trauma (National Policing Improvement Agency 2010, p. 18, 45). Further, the Bluestone unit's focus on victim care appears to have assisted in retaining a higher number of cases at the charge stage and marginally higher rate at the reached court stage, despite a greater overall withdrawal rate and higher number of complex vulnerability cases in the Bluestone sample. Early North American research that compared police responses before and after the introduction of a specialist unit found that evidence of change was quite limited and improvement 'occurred at points of least resistance' (LaFree 1989, pp. 80-89). In this regard, the Bluestone victim care, crime recording accuracy and case retention data suggest that a specialist unit can provide benefits in particularly challenging areas of policing.

In addition to the Bluestone 'team working' findings, previous research on the work of a specialist sexual assault investigation unit found that investigative team working was aided by co-location as it facilitated support, efficient decision-making and communication (van Staden and Lawrence 2010). Contemporary developments appear to be ignoring such evidence. As noted earlier, several police forces are restructuring their investigative capacity in rape cases, including Greater Manchester Police which has disbanded its specialist sexual assault investigation unit and re-deployed officers locally. While a localised response no doubt has benefits, the danger of such a move is that a concentration of expertise and associated benefits will be lost. Instead of disbanding a specialist unit, the need for localised investigation capacity might be met by a modified operational model. For example, specialist unit officers could advise and oversee investigations locally for part of their working week in the same way that CPS lawyers would regularly visit the Bluestone unit to provide regular face-to-face advice to officers (Avon and Somerset Constabulary 2011). It is difficult to see how the dispersal of officers across a force area can retain an important and arguably, unique feature of specialist units: the benefits of close team working, mutual support, and a sense of common purpose and ease of communication.

In 2017, HMICFRS acknowledged in its annual police effectiveness report, that the creation of specialist units focusing on crimes including sexual offences 'was a means to improve how they supported vulnerable people' and the staffing of those units was seen as a priority by forces (HMICFRS 2017, p. 45). A year later, HMICFRS observed that the quality gap between specialist and non-specialist investigations was 'widening', and that the use of specialist 
teams 'lead to satisfactory results for victims, who receive a good standard of service throughout' (HMICFRS 2018a, p. 51). In this report HMICFRS also expressed concern that: 'in some forces prioritising resources for specialist investigative units (supporting vulnerable victims) is having a detrimental effect on other areas of investigations. While forces must find ways to support the most vulnerable, they should not do this at the expense of other victims' ... (HMICFRS 2018a, p. 50).

There are serious contemporary challenges in supporting vulnerable victims at a time of reduced police resources, large increases in recorded allegations of rape (Office of National Statistics 2018), a national shortage of detectives, high workloads and a growth in the need for specialist officers (HMICFRS 2018a, p. 55-56). Yet, this prioritisation of resources is essential if the police service is to continue developing and improving its response to rape cases. As the 2018 HMICFRS report (2018a, p. 46-47) suggests, when referring to investigative specialism generally, this is more likely within a specialist policing context, given the performance gap between the 'generally good' specialist and 'all too often ... poor' non-specialist response. Data concerning the financial cost of creating and maintaining specialist rape or sexual offence investigation units is limited and while HMICFRS raises concern over the prioritisation of resources, it provides no robust data on cost. The research that does exist indicates inter alia that concerns around resources were the most common reason given by forces for not creating a specialist unit (Westmarland et al. 2012, p. 19). Of those forces with units, one reported that it 'top sliced' its budget to pay for the creation of the unit, other forces were unable to produce specific figures but stated that it was either 'cost neutral ... or allowed them to save money. No force seemed to think it had been a resource intensive exercise, and many had been established as part of force-wide restructures' (Westmarland et al. 2012, p. 18). Operation Bluestone was created on a cost neutral basis by the redeployment of existing resources (Avon and Somerset Constabulary 2011 , p. 2). It is thus important, given the current pressure on police budgets, not to assume that specialist units are the costliest approach. Indeed, when judging the utility of such units, any future cost/benefit analysis should take account of a wide range of contextual, investigative and other factors, including the quality and nature of victim care. The existing evidence supports the continued existence of specialist rape investigation units and indeed, 
the data on investigative specialism indicates that specialist units generally outperform 'poorly' performing non-specialist police responses (HMICFRS 2018a, pp. 46-47).

\section{Limitations}

There are of course, limitations to the current study findings and methodology. The interview data was derived from a small sample (9), and the sample size of the comparator made it difficult to perform some comparisons and prevented the use of more robust tests in several areas. Given this is the first study of its type, further research exploring the factors influencing case progression and outcomes using different models of policing, including specialist and non-specialist approaches, would further build the evidence base in this important area. Finally, and most obviously, the current study did not include victim perspectives on police investigative practices, support and care. Previous research found that victims viewed specialist units more favourably than non-specialist responses (Powell and Cauchi 2013). It would be helpful if the current study methodology could be repeated, with the inclusion of the victim perspective, to further enrich the evidence base and test these claims.

\section{Conclusion}

This study has found that the Bluestone specialist rape investigation unit delivered a number of important benefits over the comparator area. In terms of traditional performance metrics, the specialist unit delivered higher charging and 'reached court' rates, delivered more favourable outcomes in several 'live cases' measures as well as retaining a proportionally higher number of cases involving victims with multiple vulnerabilities. In addition, Bluestone officers more accurately recorded reports of rape compared to the comparator. This study also examined performance pertaining to victim care and found that the Bluestone unit outperformed the comparator in two key areas: the allocation of SAIT officers to cases and ISVA referrals. Analysis of the withdrawal data indicates that an ISVA referral was a statistically significant factor in reducing victim withdrawal in cases investigated by Bluestone. Interestingly, the comparator had more favourable findings in several areas. The overall comparator withdrawal rate was lower than for Bluestone cases. In terms of conviction rates, the comparator had a somewhat higher conviction rate in rape cases in the general sample and higher conviction rate for 'any offence' in the general 
sample and live cases. While our analysis provides various explanations for these findings, including victim age and victims presenting with multiple vulnerabilities, the overall findings are a reminder of the complexity of measuring police performance and the challenges of rape case investigation and progression that cannot be easily overcome. The police service currently operates under tight financial constraints and in the context of a large increase in recorded allegations of rape. While flexibility in the allocation of resources may be an attractive feature of non-specialist responses to rape investigation, this research indicates that investigative specialism in the form of a unit structure offers certain strengths. The qualitative data, while limited, suggested a number of positive aspects, with particular regard to team working and the building of investigative expertise. These characteristics are arguably harder to replicate in a non-specialist environment where officers work on a range of offences and, as a result, may lack the skills and expertise to work effectively with victims of rape.

Given the use of specialist units for other types of serious crime, the findings from this, and other studies, suggest that there exists a strong case for using specialist units to investigate rape. Indeed, major reviews of the police response to rape and other serious crime have endorsed the need for investigative specialism (HMICFRS 2018a) and specifically, rape and serious sexual offence investigative units (Stern 2010, Angiolini 2015). 


\section{References}

Association of Chief Police Officers., 2011. Rape Support Programme - Use of Dedicated Teams (September 2010-January 2011). London: ACPO.

Association of Chief Police Officers et al., 2010. Guidance on Investigating and Prosecuting Rape: Abridged Edition. London. Available from: http://library.college.police.uk/docs/acpo/Guidance-Investigating-Prosecuting-Rape(Abridged-Edition)-2010.pdf [Accessed 9 July 2018].

Angiolini, D.E., 2015. Report of the Independent Review into the Investigation and Prosecution of Rape in London. [Online]. Available from: https://www.cps.gov.uk/sites/default/files/documents/publications/dame_elish_angioli ni_rape_review_2015.pdf [Accessed 9 July 2018].

Association of Police and Crime Commissioners., 2015. Budget cuts will radically change policing 2015. [Online].

Available from: http://www.apccs.police.uk/latest_news/budget-cuts-will-radicallychange-policing/ [Accessed 9 July 2018].

Avon and Somerset Constabulary., 2011. Operation Bluestone. London: Home Office. [Online].

Available from: https://www.gov.uk/government/publications/operation-bluestonetilley-2011 [Accessed 9 July 2018].

Barrett, D., 2015. Don't investigate thefts, assaults or hit-and-runs, police told. The Telegraph [online] 6 August. Available from: https://www.telegraph.co.uk/news/uknews/crime/11788142/Dont-investigate-theftsassaults-or-hit-and-runs-police-told.html [Accessed 9 July 2018].

Barrett, E.C., and Hamilton-Giachritsis, C., 2013. The Victim as a Means to an End: Detective Decision Making in a Simulated Investigation of Attempted Rape. Journal of Investigative Psychology and Offender Profiling, 10, 200-218.

Beckford, M., 2018. Met Police 'risking another Worboys' after secretly disbanding it sex crime unit. Mail Online [Online] 28 January. Available from: http://www.dailymail.co.uk/news/article-5320847/Met-risking-new-Worboys-sexcrime-unit-disbanded.html [Accessed 9 July 2018].

Blair, I., 1985. Investigating Rape: A New Approach for Police. Routledge.

Braun, V., \& Clarke, V. (2006). Using thematic analysis in psychology. Qualitative Research in Psychology, 3, 77-101.

Brown, J.M., Hamilton, C., O'Neill, D., 2007. Characteristics Associated with Rape Attrition and The Role Played by Scepticism or Legal Rationality by Investigators and Prosecutors. Psychology, Crime and Law, 13(4), 355-370. 
Bryden, D.P., and Lengnick, S., 1997. Rape in the Criminal Justice System. Journal of Criminal Law and Criminology, 87(4), 1194-1384.

Bryman, A. \& Burgess, R.G. 1994, Analyzing qualitative data, Routledge.

Burton, M., Mcleod, R., De Guzmán, V., Evans, R., Lambert, H., and Cass, G., 2012. Understanding the Progression of Serious Cases through the Criminal Justice System: Evidence Drawn from a Selection of Casefiles. Ministry of Justice Research Series 11/12.

Campbell, R., 2005. What Really Happened? A Validation Study of Rape Survivors' HelpSeeking Experiences With the Legal and Medical Systems. Violence and Victims, 20, 5068.

Darwinkel, E et al., 2013. Improving police officers' perceptions of sexual offending through intensive training. Criminal Justice and Behavior, 40, 895-90.

Ellison, L.E., 2015. Responding to the Needs of Victims with Psychosocial Disabilities: Challenges to Equality of Access to Justice. Criminal Law Review, 28-47.

Farand, C., 2016. British Transport Police halts plans to scrap sexual offences unit. The Independent [Online] 2 April. https://www.independent.co.uk/news/uk/crime/transportpolice-halt-plans-to-scrap-sexual-offences-unit-a6964756.html Available from: [Accessed 9 July 2018].

Feist, A., Ashe, J., Lawrence, J., McPhee, D., and Wilson, R., 2007. Investigating and Detecting Recorded Offences of Rape. London: Home Office.

Foley, M., 1990. Rape: A Feminist Analysis of Recent Public Service Provisions for Women with Particular Reference to the Sexual Assault Referral Centre. PhD Thesis, University of Salford.

Hester, M., 2013. From Report to Court: Rape cases and the Criminal Justice System in the North East. Bristol: University of Bristol in association with the Northern Rock Foundation.

Hester, M., and Lilley, S.J., 2015. More than support to Court: ISVAs in Teeside. Bristol: University of Bristol in association with the Northern Rock Foundation.

Hine, B., and Murphy, A., 2017. The impact of victim-perpetrator relationship, reputation and initial point of resistance on officers' responsibility and authenticity ratings towards hypothetical rape cases. Journal of Criminal Justice, 49, 1-13.

Home Office., 2017. The Counting Rules for Recorded Crime. London: Home Office. 
Hohl, K., and Stanko, E.A., 2015. Complaints of rape and the criminal justice system: Fresh evidence on the attrition problem in England and Wales. European Journal of Criminology, 12(3), 324-341.

Her Majesty's Inspectorate of Constabulary., 2014. Crime-recording: making the victim count. The final report of an inspection of crime data integrity in police forces in England and Wales [Online]. London: HMIC. Available from: https://www.justiceinspectorates.gov.uk/hmicfrs/wp-content/uploads/crime-recordingmaking-the-victim-count.pdf [Accessed 9 July 2018].

Her Majesty's Inspectorate of Constabulary Rape Monitoring Group., 2015. Local Area data for 2014/15, Avon and Somerset. [Online]. London: HMIC. Available from: https://www.justiceinspectorates.gov.uk/hmicfrs/wp-content/uploads/avon-andsomerset-rmg-digest-2014-15.pdf [Accessed 9 July 2018].

Her Majesty's Inspectorate of Constabulary and Fire \& Rescue Service., 2016a. Sussex Police: Crime Data Integrity inspection 2016. [Online] HMICFRS. Available from: https://www.justiceinspectorates.gov.uk/hmicfrs/publications/sussex-crime-dataintegrity-inspection-2016/ [Accessed 9 July 2018].

Her Majesty's Inspectorate of Constabulary and Fire \& Rescue Service., 2016b. Avon and Somerset Police: Crime Data Integrity inspection 2016. [Online] HMICFRS. Available from: https://www.justiceinspectorates.gov.uk/hmicfrs/publications/avon-and-somersetcrime-data-integrity-inspection-2016/ [Accessed 9 July 2018].

Her Majesty's Inspectorate of Constabulary and Fire \& Rescue Service., 2016c. Greater Manchester Police: Crime Data Integrity inspection 2016. [Online]. Available from: https://www.justiceinspectorates.gov.uk/hmicfrs/publications/greater-manchestercrime-data-integrity-inspection-2016/ [Accessed 9 July 2018].

Her Majesty's Inspectorate of Constabulary and Fire \& Rescue Service., 2017. PEEL: police effectiveness 2016: A national overview. [Online]. Available from: https://www.justiceinspectorates.gov.uk/hmicfrs/wp-content/uploads/peel-policeeffectiveness-2016.pdf [Accessed 9 July 2018].

Her Majesty's Inspectorate of Constabulary and Fire \& Rescue Service., 2018. PEEL: police effectiveness 2017: A national overview. [Online]. Available from: https://www.justiceinspectorates.gov.uk/hmicfrs/publications/peel-policeeffectiveness-2017/ [Accessed 9 July 2018].

Her Majesty's Inspectorate of Constabulary and Fire \& Rescue Service., 2018. North Yorkshire Police: Crime Data Integrity inspection 2017. [Online] Available from: https://www.justiceinspectorates.gov.uk/hmicfrs/publications/north-yorkshire-policecrime-data-integrity-inspection-2017/\#rape [Accessed 9 July 2018].

House of Commons. Home Affairs Committee, 2014. Leadership and Standards in the Police, Third Report of Session 2013-2014. London: The Stationary Office (HC 67-1) 
House of Commons. Public Administration Select Committee, 2014. Caught Red-Handed: Why We Can't Count on Police Recorded Crime Statistics: UK Statistics Authority Response to the Committee's Thirteenth Report of Session 2013-2014, Fourth Report of Session 20142015. London: The Stationary Office (HC 645)

Horvath, M.A.H., and Yexley, M., 2012. Developments in investigative approaches to rape: the investigative heritage' in Brown, J.M., and Walklate, S.A., eds., 2012. Handbook on Sexual Violence. Routledge.

Independent Police Complaints Commission, 2010. IPCC independent investigation into the Metropolitan Police Service's inquiry into allegations against John Worboys. London: IPCC.

LaFree, G.D., 1989. Rape and Criminal Justice: The Social Construction of Sexual Assault. Wandsworth.

Lally C., 2017. Front-line gardaí will no longer investigate rapes, child sex abuse The Irish Times [Online]. 3 June. Available from: https://www.irishtimes.com/news/crime-and-law/frontline-garda\%C3\%AD-will-no-longer-investigate-rapes-child-sex-abuse-1.3106184

[Accessed 9 July 2018].

Lea, S.J., Lanvers, U., and Shaw, S., 2003. Attrition in Rape Cases: Developing a Profile and Identifying Relevant Factors. The British Journal of Criminology, 43(3), 583-599.

Lloyd, S., and Burman, M., 1996. Specialist Police Units and the joint investigation of child abuse. Child Abuse Review, 5(1), 4-15.

Lonsway, K.A., Welch, S., and Fitzgerald, L.F., 2001. Police training in sexual assault response: Process, outcomes, and elements of change' Criminal Justice and Behavior, 28(6), 695-730.

Nowell, L.S., Norris, J.M., White, D.E. \& Moules, N.J. 2017, "Thematic Analysis: Striving to Meet the Trustworthiness Criteria", International Journal of Qualitative Methods, vol. 16, $1-13$

Metropolitan Police Authority, 2002. Scrutiny Report: Rape Investigation and Victim Care. London: MPA. [Online]. Available from: http://policeauthority.org/metropolitan/downloads/scrutinites/rape-scrutiny.pdf [Accessed 9 July 2018]

Metropolitan Police Authority, 2002a. MPS Project Sapphire Strategy Action Plan 2002-2003. [Online]. Available from: http://policeauthority.org/Metropolitan/committees/xpspm/2002/020613/07/index.html [Accessed 9 July 2018].

Metropolitan Police 2018. [Online]. Strengthening Local Policing Programme. Available from: https://www.met.police.uk/SysSiteAssets/media/downloads/met/aboutus/strengthening-local-policing-programme.pdf [Accessed 9 July 2018] 
McGlynn, C., and Westmarland, N., 2018. Kaleidoscopic Justice: Sexual Violence and VictimSurvivors' Perceptions of Justice. Social and Legal Studies, 1-23 [Online]. Available from: http://journals.sagepub.com/doi/pdf/10.1177/0964663918761200 [Accessed 9 July 2018].

McMillan, L., 2015. The role of the specially trained officer in rape and sexual offence cases. Policing and Society, 25(6), 622-640

Ministry of Justice et al., 2013. An Overview of Sexual Offending in England and Wales. London. [Online]. Available from: https://assets.publishing.service.gov.uk/government/uploads/system/uploads/attachm ent_data/file/214970/sexual-offending-overview-jan-2013.pdf [Accessed 9 July 2018]

Murphy, A., and Hine, B., 2018. Investigating the demographic and attitudinal predictors of rape myth acceptance in U.K. Police officers: developing an evidence-base for training and professional development. Psychology, Crime and Law

Office for National Statistics, 2018. Crime in England and Wales: year ending March 2018.

[Online]. Available from:

https://www.ons.gov.uk/peoplepopulationandcommunity/crimeandjustice/bulletins/cri meinenglandandwales/yearendingmarch2018[Accessed 16 October 2018].

Pettitt, B., Greenhead, S., and Khalifeh, H., 2013. At Risk, Yet Dismissed: The Criminal Victimisation of People with Mental Health Problems. London: Victim Support; Mind. Available from: https://www.mind.org.uk/media/187663/At-risk-yet-dismissedreport_FINAL_EMBARGOED.pdf [Accessed 9 July 2018]

Powell, M.B., and Wright, 2011-2012. Professionals' Perceptions of a New Modal of Sexual Assault Investigation Adopted by Victoria Police. Current Issues Crim. Just., 23, 333.

Powell, M.B., and Cauchi, R., 2013. Victims' perceptions of a new model of sexual assault investigation adopted by Victoria Police. Police Practice and Research, 228, 14(3), 228241.

Regoeczi, W.C., and Hubbard, D.J., 2018. The Impact of Specialized Domestic Violence Units on Case Processing. American Journal of Criminal Justice, 1-21.

Robinson, A., 2009. Independent Sexual Violence Advisors: A Process Evaluation. London: Home Office. [Online]. Available from: https://orca.cf.ac.uk/24241/1/isvareport.pdf [Accessed 9 July 2018].

Sleath, E., and Bull, R., 2012. Comparing Rape victim and Perpetrator Blaming in a Police Officer Sample: Differences Between Police Officers With and Without Special Training. Criminal Justice and Behavior, 39(5), 646-665. 
Sleath, E., and Bull, R., 2017. Police Perceptions of Rape Victims and The Impact on Case Decision Making: A Systematic Review. Aggression and Violent Behavior, 34, 102-112.

Stanko, B., and Williams, E., 2009. Reviewing Rape and Rape Allegations in London: What are the Vulnerabilities of the Victims who Report to the Police? in Horvath, M.A.H., and Brown J.M., eds., 2009. Rape: Challenging Contemporary Thinking. Cullompton: Willan.

Van Staden, L., and Lawrence, J., 2010. A qualitative study of a dedicated sexual assault investigation unit. Research Report 48. London: Home Office. [Online]. Available from: https://assets.publishing.service.gov.uk/government/uploads/system/uploads/attachm ent_data/file/116562/horr48-report.pdf [Accessed 9 July 2018].

Westmarland, N., Aznarez, M., Brown, J., and Kirkham, L., 2012. The Benefits of Police Specialist Rape Teams. A report commissioned and funded by the Association of Chief Police Officers.

Williams, J., and Keeling, N., 2017. Greater Manchester Police's specialist sex crime unitwhich investigates serious sexual offences including rapes - is to be disbanded. Manchester Evening Post [Online]. 23 October. Available from: https://www.manchestereveningnews.co.uk/news/greater-manchester-news/gmpsspecialist-sex-crime-unit-13802369 [Accessed 9 July 2018]. 